\title{
Colorectal Cancers in Mauritania: Clinical Aspects and Treatment
}

\author{
A. Sarr ${ }^{1 *}$, A. H. Isselmou ${ }^{2}$, E. A. M. Horma Babana ${ }^{2}$, D. Diédhiou${ }^{1}$, A. Horma Babana², M. Ndour Mbaye ${ }^{1}$, \\ D. Sow ${ }^{1}$, S. N. Diop ${ }^{1}$
}

${ }^{1}$ Department of Internal Medicine, Abass Ndao Hospital Centre, Cheikh Anta Diop University, Dakar, Senegal

${ }^{2}$ Department of Internal Medicine, Nouakchott National Hospital Centre, Nouakchott, Mauritania

Email: *annasarr@orange.sn, isselmou.ouldabdelhamid@gmail.com, Hassan.horma@gmail.com,dembadiedhiou1976@gmail.com,

mbayester@gmail.com,drdjiby@yahoo.fr, saidnorou@yahoo.fr

How to cite this paper: Sarr, A., Isselmou, A.H., Babana, E.A.M.H., Diédhiou, D., Babana, A.H., Mbaye, M.N., Sow, D. and Diop, S.N. (2016) Colorectal Cancers in Mauritania: Clinical Aspects and Treatment. Open Journal of Internal Medicine, 6, 139-146. http://dx.doi.org/10.4236/ojim.2016.64019

Received: November 8, 2016

Accepted: December 18, 2016

Published: December 21, 2016

Copyright $\odot 2016$ by authors and Scientific Research Publishing Inc. This work is licensed under the Creative Commons Attribution International License (CC BY 4.0).

http://creativecommons.org/licenses/by/4.0/

\begin{abstract}
The aim of our study was to determine epidemiological, clinical and therapeutic profile of colorectal cancers in Mauritania. Patients and Methods: It was a retrospective multicentric study conducted over 5 years in Nouakchott National Hospital Centre and in private clinics of Mauritania. All cases of colorectal cancers histologically confirmed were included. The Astler and Coller classification was used to classify lesions by level of extension. Results: 225 patients were included with a sex ratio (M/F) of 1.39 , an average age of 52.3 years. Location of the lesion was rectal (37.7\%) and colonic $(62.3 \%)$. Clinical manifestations were dominated by rectal bleeding $(26.9 \%)$, occlusive syndrome (16.5\%) and transit disorders (11.6\%). Endoscopic lesions were of stenosing (45.2\%), ulcero-burgeoning (39\%), ulcerous (7.5\%) and burgeoning (4.7\%) types. Histological profiles were adenocarcinoma (88.9\%), carcinoma (3.1\%) and lymphoma (2.6\%). The work-up for extension revealed metastasis in $33.6 \%$ of cases. These were stage B (49\%) and C (36\%) among the 95 cancers that received the Astler and Coller classification. The treatment was curative (80.83\%) and palliative (19.16\%). Conclusion: Colorectal cancer is a reality in Africa. However, its diagnosis still remains delayed, which increases the prognosis, hence the need to promote screening tests.
\end{abstract}

\section{Keywords}

Colorectal Cancer, Diagnosis, Prognosis, Mauritania

\section{Introduction}

At global level, colorectal cancer (CRC) is the most common digestive cancer [1]. In 
Europe, its incidence is high due to population ageing. Its prognosis was improved through the development of screening and treatment of pre-cancerous lesions [2] [3]. In Africa, colorectal cancer data are mainly derived from endoscopic and surgical series. This is a male ailment between 45 and 60 years [4]. In Senegal, often late diagnosis is made in patients with rectal bleeding in $45 \%$ and occlusive syndrome in $31 \%$ of cases [5]. In Sub-Saharan Africa, adenocarcinoma of Lieberkünien type is the predominant histological type in over $97 \%$ of cases [6] [7] [8]. The prognosis remains poor with a low 5-year survival [5]. The aim of this Senegalese-Mauritanian study was to determine epidemiological, clinical and therapeutic profile of colorectal cancer in Mauritania, a buffer country between the Maghreb and Black Africa.

\section{Patients and Methods}

It was a descriptive retrospective multicentricstudy of 225 cases of colorectal cancer conducted from 1 January 2008 to 31 December 2012 at the National Hospital Centre of Nouakchott (in internal medicine, hepato-gastroenterology, anatomypathology and general surgery departments) and in private clinics of the capital city (Nouakchott, Mauritania). All cases of colorectal cancers histologically confirmed were selected and those with incomplete files were not included. Recruitment was carried out from the hospital records. The register of the anatomy pathology departments was also used for histological reports of biopsies and surgical specimens. Data were collected from a predetermined survey sheet including:

- Sociodemographic data: age, sex, antecedent.

- Clinicaldata: discovery circumstances, clinical signs, associated pathologies, lower gastro intestinal endoscopy (location, macroscopic aspects), computed tomography (extension work-up), complete blood count, and histological data. The Astler and Coller Classification [9] made it possible was used to classify lesions by level of extension.

- Treatment Data: chemotherapy, surgery, radiotherapy as appropriate.

Data entry was carried out using the Epi Info software version 6 and Microsoft Excel. For analysis purposes, the following statistical tests were used: percentage, average.

\section{Results}

\subsection{Sociodemographic Aspects}

225 cases were included. These were 131 men and 94 women, i.e. a sex ratio (M/F) of 1.39. The average age was 52.3 years ( 4 - 90 years extremes). The most affected age group was between 46 - 60 years (41.3\%), followed by those over 60 years (27.1\%). Patients under 30 years were involved in $8 \%$ of cases. In our series, 126 patients (56\%) were black (86 Harratin, 39 Black African Mauritanian and 1Senegalese) and 99 other (44\%) Caucasians (98 Moors and 1 Iraqi).

\subsection{History and Aetiological Factors}

An adenomatous polyp was found in 7 patients and anadenomatous polyposis in 3 pa- 
tients. In 4 patients there was a tumour recurrence (three rectal and one sigmoid location). Only one family history of colorectal cancer was found.

\subsection{Clinical Aspect}

The main clinical manifestations were: rectal bleeding (26.9\%), occlusive syndrome (16.5\%). The other symptoms were weight loss (13.5\%), transit disorders (11.6\%), rectal syndrome $(6.4 \%)$, anal mass or haemorrhoidal syndrome $(6.2 \%)$, clinical anaemia (4.4\%), abdominal mass (4.4\%) and appendiceal syndrome (1.3\%) (Table 1).

\subsection{Endoscopic Aspects}

Low gastro intestinal endoscopy was performed in $64.8 \%$ of patients (92 sigmoidoscopies and 54 colonoscopies) and abdominal tomography in $21.1 \%$ of cases. Colorectal cancers were divided into 85 rectal cancers (37\%) and 142 colon cancers (63\%). Two cases of synchronous localizations (caecum and colon caecum + left-sided colon and caecum + recto sigmoid) were found. Endoscopic lesions were of the stenosing (45.2\%), ulcero-burgeoning (39\%), ulcerous (7.5\%) and burgeoning types (4.7\%). Table 2 shows the distribution of colorectal cancers by location.

\subsection{Biological and Histological Aspects}

Tumour markers (CEA and CA 19-9) were assayed in 25 patients (11.1\%). A high rate was found in 10 of them (40\%). Anaemia was presented in 16 patients. An anatomopathological examination revealed adenocarcinoma in $88.9 \%$ of cases. Table 3 shows the frequency of different histological types.

\subsection{Evaluation of Extension}

125 patients underwent a CT scan (103 colon cancers and 22 rectal cancers). Overall,

Table 1. Symptoms ofcolorectal cancers according location.

\begin{tabular}{lccc}
\hline Symptoms & $\begin{array}{c}\text { Rectum } \\
(\mathrm{n}=\mathbf{8 5})\end{array}$ & $\begin{array}{c}\text { Right-sided colon } \\
(\mathrm{n}=53)\end{array}$ & $\begin{array}{c}\text { Left-sided colon } \\
(\mathrm{n}=\mathbf{8 9})\end{array}$ \\
\hline Rectal bleeding & $68.2 \%$ & $11.3 \%$ & $26.9 \%$ \\
Weight loss & $17.6 \%$ & $20.7 \%$ & $20.2 \%$ \\
Anaemia & $4.7 \%$ & $11.3 \%$ & $3.3 \%$ \\
Pain & $14.1 \%$ & $33.9 \%$ & $32.5 \%$ \\
Diarrhoea & $7 \%$ & $16.9 \%$ & $13.4 \%$ \\
Constipation & $8.5 \%$ & $20.7 \%$ & $11.2 \%$ \\
Rectal syndrome & $12.9 \%$ & $0 \%$ & $1.1 \%$ \\
Occlusion & $4.7 \%$ & $30.1 \%$ & $38.2 \%$ \\
Appendicular syndrome & $0 \%$ & $5.6 \%$ & $0 \%$ \\
Anal mass/Haemorrhoidal syndrome & $15.2 \%$ & $1.8 \%$ & $0 \%$ \\
Anorectal fistula & $1.1 \%$ & $0 \%$ & $0 \%$ \\
\hline
\end{tabular}


Table 2. Distributionof cancers by location.

\begin{tabular}{cccc}
\hline Localisation of colorectal cancers & Series & Sex-ratio (H/F) & Percentage \\
\hline Caecum & 13 & $5 / 8$ & $9 \%$ \\
Right-sided colon $\quad$ Ascending colon & 35 & $23 / 14$ & $26 \%$ \\
Colonic corner & 2 & & $4 \%$ \\
Transverse colon & 5 & $2 / 3$ & $23 \%$ \\
Left-sided colon $\quad$ Cescending colon & 28 & $19 / 13$ & $39 \%$ \\
Sigmoid & 4 & & $37 \%$ \\
Rectum & 55 & $61 / 24$ &
\end{tabular}

Table 3. Frequency and topographical distribution ofhistological types of CRC.

\begin{tabular}{lll}
\hline HISTOLOGICAL TYPES & \multicolumn{2}{c}{ Series (n= 225) } \\
\hline Adenocarcinoma & 200 & $88.8 \%$ \\
Well-differentiated Luberkhunien & 139 & $61.7 \%$ \\
Moderately differentiated Luberkhunien & 34 & $15.1 \%$ \\
$\quad$ Poorly differentiated Luberkhunien & 5 & $2.2 \%$ \\
$\quad$ Mucinous & 22 & $9.7 \%$ \\
Carcinoma & 7 & $3.1 \%$ \\
$\quad$ Epidermoid & 4 & $1.7 \%$ \\
$\quad$ Poorly differentiated & 2 & $0.8 \%$ \\
$\quad$ Polymorphous & 1 & $0.4 \%$ \\
Lymphoma & 6 & $2.6 \%$ \\
Malignant undifferentiated tumour & 4 & $1.7 \%$ \\
Mixed tumour & 3 & $1.3 \%$ \\
Tumour with spindle-shaped cells GIST & 1 & $0.4 \%$ \\
Melanoma & 1 & $0.4 \%$ \\
Leiomyosarcoma & 1 & $0.4 \%$ \\
Neuroendocrinecarcinoma & 1 & $0.4 \%$ \\
\hline
\end{tabular}

metastasis was found in 42 patients (33\%). Of the 103 colon cancers, 29 cases (28\%) of metastasis were found (11 livers, 6 lung, 8 peritoneal carcinosis, 6 lymph node, 4 small intestines, 7 adnexal and 1 brain). Of the 22 rectal cancers, there wasa metastasis in 13 cases (59\%) (3 livers, 6 lungs, 5 adnexal, 2 lymph node, 1 small intestine and 1 peritoneal carcinosis). Only 95 cancers received the Astler and Coller classification presented in Table 4.

\subsection{Therapeutic Aspects}

Among the 225 patients, $167(74.2 \%)$ received treatment. The remaining 58 (25.7\%) 
Table 4. Classification of cancers according Astler and Coller classification.

\begin{tabular}{cccccc}
\hline $\begin{array}{c}\text { Astler and Coller } \\
\text { Classification }\end{array}$ & Series & & $\begin{array}{c}\text { Right-sided } \\
\text { colon }\end{array}$ & $\begin{array}{c}\text { Left-sided } \\
\text { colon }\end{array}$ & Rectum \\
\hline A & 0 & $0 \%$ & 0 & 0 & 0 \\
B & 47 & $49 \%$ & 17 & 23 & 7 \\
C & 34 & $36 \%$ & 11 & 17 & 6 \\
D & 14 & $15 \%$ & 6 & 6 & 2 \\
Total & 95 & $100 \%$ & 33 & 47 & 15 \\
\hline
\end{tabular}

were lost to follow-up. The treatment was curative (surgery) in 135 cases $(80.83 \%)$ and palliative (chemotherapy or radiation) in 32 cases (19.1\%). Curative treatment involved $44(86.2 \%)$ cancers of the right-sided colon, $47(79.6 \%)$ cancers of the left-sided colon and $45(78.9 \%)$ of rectal cancers.

\section{Discussion}

Difficulties of this study are related to its retrospective nature and the high number of patients lost to follow-up.

This article is derived from a retrospective study conducted in a university hospital for a thesis of medicine. This kind of work doesn't require in Senegal and in Mauritania the approval of ethic committee.

\subsection{Epidemiological Data}

The African series on colorectal cancer are primarily derived from hospital data. Over a period of 5 years, 225 cases of CRC were collected. This figure is higher than those found in Senegal by Sarr et al. [10] and Konate et al. [5] who reported 15 and 71 cases, respectively. In Togo, Darré et al. [11] in the pathology department reported 57 colorectal cancers over a 10 year period, representing $2.8 \%$ of all cancers.

The average age of 52.3 years corroborates with the African data [5] [7] [12]. Averages of younger age are reported by others [13] [14]. This predominance of cases prior to the sixth decade was also reported in the United States among African-Americans [15]. In the Europe, colorectal cancer occurs more frequently in elderly persons [1] [2] [3]. Colorectal cancer is a predominantly male condition. However, Sarr et al. [10] in Senegal, Diarra et al. [8] in Mali and Diallo et al. [13] [15] in Gabon reported a sex ratio in favour of women.

In our series, $56 \%$ were black people and $44 \%$ white people. A North American study conducted by Sangeeta et al. [16] reported an increase in CRC incidence in AfricanAmericans compared to white people. Apart from genetic predisposition, environmental factors and poverty limiting access to health care are probably involved.

\subsection{Clinical Aspects}

Rectal bleeding was the CRC discovery circumstance in $26.9 \%$ of cases. This symptom 
is quite frequently reported by African authors in proportions of 43 to $46 \%$ [5] [13]. It is usually the proof indicative of a rectal injury (65\% in this location). Saïdi et al. [17] in Kenya found it in $79 \%$ of rectal localization and $21 \%$ of colon among 253 CRCs. Occlusive syndrome usually complicates left-sided colonic tumour. This is a symptom of poor prognosis. In the series of 22 cancers revealed by an occlusion of Konaté et al. [6], $50 \%$ of patients died within a year after surgery. The frequency of other revealing manifestations varies according the authors [6] [10] [13].

The diagnosis of CRC was established through the lowerendoscopy in $65 \%$ of cases. In the surgical series, the endoscopy achievement rate is lower between $49 \%$ and $56.4 \%$ [5] [13]. This low achievement rate is probably due to the lack of equipment and sometimes to a peroperative revelation. In most studies, colonic location predominates. Konaté et al. [5] in Senegal reported more colonic locations in 59.2\% against $40.8 \%$ in the rectum. A similar distribution is found in Gabon with $57 \%$ and $42 \%$, respectively [13]. However, a more rectal location was reported in Marocco in 57\% [15].

\subsection{Histological Aspects and Extension}

Adenocarcinoma is the predominant histologic lesion (88.9\%). This is in accordance with African and international literature data. Carcinomas come second with 3.1\% [1] [2] [3] [11] [12] [15]. Thoracic-abdominal-pelvic tomography scanis the gold standard for extension work-up. However, only $55 \%$ of our patients received it due to financial inaccessibility. None of our patients underwent a rectal echo endoscopy because of unavailability of the latter. Overall, metastasis was found in 42 patients (33\%). Of the 103 colon cancers, 29 cases (28\%) of metastasis were found. Of the 22 rectal cancers, there was a metastasis in 13 cases (59\%).

\subsection{Classification}

In Africa, colorectal cancer is diagnosed at a later stage. Of the 95 cancers that received the Astler and Coller classification, $49 \%$ were discovered at a stage where the tumour did not enter through the colonic wall (Stage B), 36\% already had a loco-regional invasion (Stage C) and 15\% were metastatic (Stage D). In Mali, Traoré et al. [18] reported $28.8 \%, 50 \%$ and $21.2 \%$ for the stages II, III and IV, respectively using the TNM classification. In the Gabonese series [13], patients in stages II and III represented 34\% and $46 \%$, respectively. Similar data are reported in the Maghreb with $41.6 \%$ for stage II and $37.5 \%$ for stage III [12]. However, in Europe and the United States the diagnosis is madeat an earlier stage through mass screening and in patients at risk [1] [3] [4] [16].

\subsection{Treatment and Survival}

Only $74.2 \%$ underwent surgery and $37 \%$ received adjuvant treatment. Our national oncology center that can provide this treatment was only established in 2010 and the cost of treatment is borne by patients. In rectal cancer, Bonjer et al. [19] report similar results between open surgery and laparoscopy. In our series, we were not able to study the survival because of the retrospective nature of the study and the high percentage of 
lost to follow-up. African data show a low rate of 5-year survival. In Senegal, it stands at $5 \%$ in colorectal cancer and 15\% in rectal cancer [6] [7]. In 25 European Union countries the average value of the 5-year survival is greater than $50 \%$ [1]. In these countries, the screening and treatment of polyps as well as mass screening account for this improved prognosis [20]. However, there is a need to improve education on CRC screening [21].

\section{Conclusion}

Colorectal cancer is not rare in Africa as is evident from reported cases. Its diagnosis is later and its prognosis is poor. Adenocarcinoma is the most common histological type.

\section{Suggestions}

It is essential to promote access to endoscopy but also screening tests in persons at risk. Diagnosis and treatments centers should be implemented by the decisors markers.

\section{References}

[1] Lambert, R. (2009) Colorectal Cancer Epidemiology. Cancero Digest, 1, 2-6.

[2] Corlzy, D.A., Jensen, C., Marks, A.R., et al. (2014) Adenoma Detection and Risk of Colorectal Cancer and Death. New England Journal of Medicine, 370, 1298-1306. https://doi.org/10.1056/NEJMoa1309086

[3] Loberg, M., Kalager, M., Oyvind, H., et al. (2014) Long Term Colorectal Cancer Mortality after Adenoma Removal. New England Journal of Medicine, 371, 799-807. https://doi.org/10.1056/NEJMoa1315870

[4] Salamatou, M.G., Hinde, H., Abdelmadjid, S. and Ali, Q. (2014) Digestif Cancer in Niger. Relative Frequency by a Retrospective Study Conducted since 1992 to 2009. European Scientific Journal, 10, 1857-1881.

[5] Konaté, I., Sridi, A., Ba, P.A., et al. (2012) Descriptive Study of Colorectal Cancer to the Surgical Clinic of the CHU Aristide Le Dantec in Dakar. Journal Africain du Cancer, 4, 233-237.

[6] Konaté, I., Cissé, M., Diallo-Owono, F.K., et al. (2009) Management of Colorectal Cancers at the Stage of Intestinal Occlusion at the Department of Surgery of Aristide le Dantec Teaching Hospital Dakar Senegal. Bull Med Owendo, 12, 31-33

[7] Dem, A., Diallo-Owono, F.K., Dieng, M.M., Gaye, P.M., Diouf, D. and Ka, S. (2011) Diagnostic and Therapeutic Aspects of Rectal Cancers to the Institute of the Cancer from Dakar to Senegal. Rev Afri Chir and Spéciality, 5, 25-28.

[8] Diarra, M., Konate, A. and Traore, C.B. (2012) Epidemiology of the Digestive Cancers in a Hospital Environment in Bamako. Hegel, 2, 12-22.

[9] Astler, V.B. and Coller, F.A. (1954) The Prognostic Significance of Direct Extension of Carcinoma of the Colon and Rectum. Annals of Surgery, 139, 846652. https://doi.org/10.1097/00000658-195406000-00015

[10] Sarr, A., Ndour Mbaye, N.M., Diop, S.N., Ka Cisse, M.S., Evra, M.L. and Diédhiou, D. (2010) Low Digestive Pathology of the Senegalese: Contribution of 241 Examinations Realized in the Center of Digestive Endoscopy of the Hospital Center Abass Ndao. Revue du CAMES, 11, 135-138.

[11] Darré, T., Amégbor, K., Napo-koura, G., et al. (2014) Profil histo-épidémiologique des 
cancers colorectaux au Togo. Journal Africain d Hépato-Gastroentérologie, 8, 226-229. https://doi.org/10.1007/s12157-014-0568-2

[12] Toumi, A.A., Ben Mahmoud, L.K., Khiari, M., et al. (2010) Epidemiological Study, Pathologic Evaluation and Prognostic Factors of Colorectal Mucinous Adenocarcinoma VS Non Mucinous (about a Series of 196 Patients). Tunisie Medicale, 88, 12-17.

[13] Diallo-Owono, F.K., Nguema, M.R., Ibada, J., Mihindou, C. and Ondo N’Dong, F. (2011) Epidemiological and Diagnostic Features of Colorectal Cancer in Libreville, Gabon. Medecine Tropicale, 71, 605-607.

[14] Diarra, A., Konate, A., Diarra, A.S., Kalle, A., Dembele, M. and Diallo, G. (2006) Colorectal Cancers in Tropical Environment. Acta Endoscopia, 36, 187-193. https://doi.org/10.1007/BF03006414

[15] El House, H., Ajbara, W., Amsaguine, S., El Amrani, N., Drissi, H., Ahallat, M. and Radallah, D. (2015) Epidemiological and Clinicopathological Profile in Moroccan Population with Colorectal Cancer. African Journal of Cancer, 7, 95-99. https://doi.org/10.1007/s12558-014-0352-3

[16] Agrawal, S., Bhupinderjit, A., Bhutani, M.S., et al. (2005) Colorectal Cancer in African Americans. The American Journal of Gastroenterology, 100, 515-523. https://doi.org/10.1111/j.1572-0241.2005.41829.x

[17] Saidi, H.S., Karuri, D. and Nyaim, E.O. (2008) Correlation of Clinical Data, Anatomical Site and Disease Stage in Colorectal Cancer. East African Medical Journal, 85, 259-262. https://doi.org/10.4314/eamj.v85i6.9622

[18] Traore, B., Zongo, N., Diallo, T.M., et al. (2014) Anatomicals Clinical and Therapeutics Aspects of the Primitive Malignant Tumors of the Abdominal Wall in Two Services of Surgery of Western Africa. Rev Afri Chir and Spécialités, 8, 39-45.

[19] Bonjer, H.J., Deijen, C.L., Abis, G.A., et al. (2015) A Randomized Trial of Laparoscopic versus Open Surgery for Rectal Cancer. New England Journal of Medicine, 372, 1324-1332. https://doi.org/10.1056/NEJMoa1414882

[20] Nishihara, R., Wu, K., Lochhead, P., et al. (2013) Long Term Colorectal Cancer Incidence and Mortality after Lower Endoscopy. New England Journal of Medicine, 369, 1095-1105. https://doi.org/10.1056/NEJMoa1301969

[21] Idowu, K.A., Adenuga, B., Otubu, O., et al. (2016) Place of Birth, Cancer Beliefs and Being Current with Colon Cancer Screening among US Adults. Annals of Gastroenterology, 29, 336-340. https://doi.org/10.20524/aog.2016.0040 
Submit or recommend next manuscript to SCIRP and we will provide best service for you:

Accepting pre-submission inquiries through Email, Facebook, LinkedIn, Twitter, etc. A wide selection of journals (inclusive of 9 subjects, more than 200 journals)

Providing 24-hour high-quality service

User-friendly online submission system

Fair and swift peer-review system

Efficient typesetting and proofreading procedure

Display of the result of downloads and visits, as well as the number of cited articles

Maximum dissemination of your research work

Submit your manuscript at: http://papersubmission.scirp.org/

Or contact ojim@scirp.org 